\title{
COMPOSITE LAMINATES FOR AUTOMOTIVE BUMPERS AND LIGHTWEIGHT SUPPORT STRUCTURES
}

\author{
R. Chatys", M. Kleinhofs ${ }^{* *}$, A. Panich ${ }^{* * *}$, G. Miśków ${ }^{\dagger}$
}

\begin{abstract}
Sandwich-structured composites fabricated by vacuum bag molding were studied to determine their suitability for use in automotive bumpers and lightweight support structures. The carbonfiberfiberglass-epoxy composites with Soric XF, PP honeycomb or Coremat-Xi cores were subjected to impact resistance and three-point bending tests to analyze their behavior at higher deformation rates. The results reveal that their good impact absorption capacity and bending resistance were due to their structural complexity.
\end{abstract}

Keyword: composite laminate, impact resistance, three-point bending, vacuum bag molding, bumper

\section{Introduction}

Composites, particularly polymer-matrix composite laminates, are increasingly used for elements capable of absorbing energy from impact loads while undergoing deformation (Morello L, et al., 2011). The energy absorbed $E_{p}$ by an object with a certain mass $m$ moving with a predetermined velocity $V$ during a collision with a fixed obstacle can be determined from the following relationship

$$
\mathrm{E}_{\mathrm{p}}=\mathrm{mV}^{2} / 2
$$

Materials with high impact resistance are required for a great number of applications (Chatys, 2013) including controlled mobile systems (Takosoglu, 2016), for example, unmanned aerial vehicles. Such materials are also desirable for elements of an automotive bumper system protecting the front and rear ends of a motor vehicle (especially, the front frame rail and the engine compartment), which need to withstand small impact loads during a collision (Roy et al., 2014). Materials used for this purpose include glass- or carbon-fiber reinforced composites or sandwich-structured composites with a thermoset or thermoplastic matrix. Before the 1970s, bumpers were made of rolled steel, stainless steel or chrome plated steel and they were designed to absorb low-speed impact only. Chrome plated bumpers featured decorative rather than protective function. Today, bumpers are incorporated into the bodywork for better aerodynamics. They are part of a crashworthy structure (Fig. 1) and as such they need to meet the RCAR (Research Council for Automobile Repairs) safety standards to transmit the impact force ranging between 3.858 and $6.680 \mathrm{~J}$ (at $\mathrm{m}=1000 \mathrm{~kg}$ and $\mathrm{V}=10-15 \mathrm{~km} / \mathrm{h}$ ).

When impact loads are applied to bumpers and deformations occur in them under different collision situations, the energy absorbed is distributed throughout the structure. A variety of devices supporting the bumper system and absorbing and transmitting impact energy (Fig. 2) are used to reduce the risk of injuries when in contact with pedestrians. A bumper has a soft nose with an outer flexible plastic shell (a),

\footnotetext{
Research Assistant Rafał Chatys, Hab. Ph.D.Sc. Eng.: Faculty of Mechatronics and Mechanical Engineering, Kielce University of Technology, al. 1000-lecia P.P. 7; 25-345, Kielce; PL, chatys@tu.kielce.pl

** Martinsh Kleinhofs, Prof. Hab. Ph.D.Sc. Eng.: Department of Aerial Vehicle Theory and Construction, Aeronautics Institute Riga Technical University, Lomonosova 1, Riga LV 1019, Latvia; LV, e-mail: martins.klenhofs@inbox.lv

*** Aleksanders Panich, M.Sc. Eng.: Department of Aerial Vehicle Theory and Construction, Aeronautics Institute Riga Technical University, Lomonosova 1, Riga LV 1019, Latvia; LV, e-mail: aleksandrs.panichs@gmail.com

$\dagger$ Gracjan Miśków, M.Sc. Eng.: PHOENIX EQUIPMENT POLSKA, ul. Jodłowa 54, 77-200 Miastko; PL, biuro@phoenixequipment.pl
} 
thermoset as polyurethane molded element by Reaction Injection Molding (RIM) or thermoplastic injection molded as polyolefin or polycarbonate or blended thermoplastics. The metal support crossmember (b) attached to the body frame using energy absorbing devices has inserts made of polyurethane, polypropylene or polystyrene foam (c), as well as plastic inserts -polypropylene or polystyrene honeycomb injected into the system.

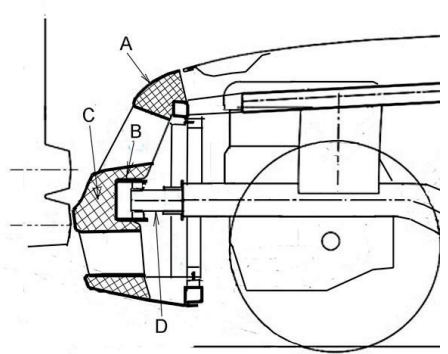

Fig. 1: Diagram of the front bumper (Morello L, 2011): A) flexible skin; B) supporting bar; C) foam insert; D) absorbing/damping device.

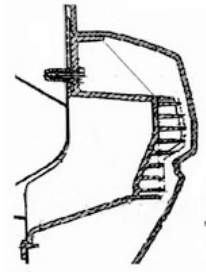

A

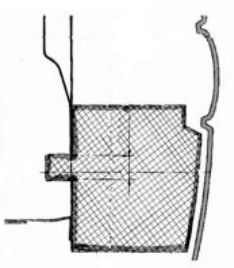

$\mathrm{B}$

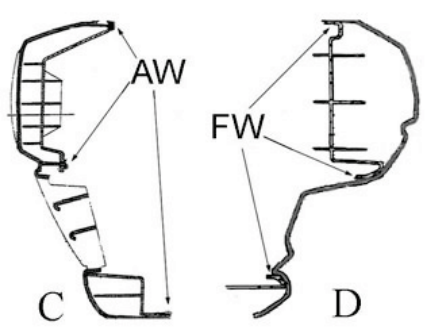

$\mathrm{D}$
Fig. 2: Bumper elements with high energy absorption capacity (Morello L, 2011): A) rigid plastic insert; B) foam insert; C) boxed plastic molding, fitted to the bumper by local heat staking; D) boxed plastic molding, fitted to the bumper by friction welding. (AW- heat staking; $F W$ - friction welding)

\section{Materials and methods}

The vacuum bag molding method was used to fabricate the sandwich-structured composites. The materials were formed at the Laboratory of Composite Materials of the Kielce University of Technology. Rymatex biaxal carbon woven cloth and fiberglass fabric $\left[0^{\circ} /-90^{\circ}\right]$ with a basis weight of $600 \mathrm{~g} / \mathrm{m}^{2}$ constituted the polymer reinforcement. Details of the formation process are provided in (Chatys et al., 2017). First, the mold surface was polished and the first layer of epoxy resin was applied. Then, the carbon fiber and fiberglass fabrics were placed and impregnated with more epoxy resin. Next, the twolayer reinforcement was bonded to the core, i.e. Lantor Soric XF, PP honeycomb or Coremat Xi. Finally, the upper skins, i.e., carbon fiber and fiberglass fabrics were placed. At the top, there was a peel ply, a breather and a perforated release film. Finally, the vacuum was drawn and the curing process began. The formation took place at a pressure of -0.9 bar. The composite plates were cut into test pieces, each having dimensions according to the PN-EN 10002-1+ACI standard. The cutting was performed with an A.P.W2010BB waterjet cutting system (Nowakowski et al., 2016) at a cutting speed of $0.8 \mathrm{~m} / \mathrm{s}$. The specimens were subjected to three-point bending with an Instron 8874. The impact resistance of the composite materials was determined through Charpy impact tests according to the PN-EN ISO 179-2 standard. Horizontally mounted unnotched specimens with dimensions of $120 \times 10.5 \times 5-18.5 \mathrm{~mm}$ were used. The experiments were carried out at the Kaniów-based Bielsko Technological Park Laboratory using an Instron CEAST 9050 with a 25J hammer.

\section{Results and discussion}

The impact resistance tests were performed for horizontally mounted specimens at a temperature of $23{ }^{\circ} \mathrm{C}$. They were struck with a $25 \mathrm{~J}$ hammer. The aim of the tests was to determine the amount of dynamic energy (work) required to break a standardized test piece (Table 5). The tests were conducted for laminates $\mathrm{A}, \mathrm{B}$ and $\mathrm{C}$ produced by vacuum bag molding. The results indicate that the sandwich-structured composites have a capacity to absorb energy (or work) ranging from 3.858 to $6.680 \mathrm{~J}$ when they collided with a fixed barrier with $\mathrm{V}=10-15 \mathrm{~km} / \mathrm{h}$ (formula 1 ).

The failure of the specimens was due to the shear at the interfaces and in the resin layer between the carbon fiber fabric and the fiberglass fabric. The average values of impact resistance $\left(\mathrm{R}_{\mathrm{e}}\right)$ were determined using three specimens of each laminate type (Table 1). The highest impact resistance was reported for laminate A (with a Soric XF core - Chatys et al., 2017), where there was a crack propagating through the layers and plastic deformation of the core. Greater damage to the structure was observed in laminates $\mathrm{B}$ and $\mathrm{C}$, where there was plastic deformation of the core and single-sided delamination, i.e. separation of the composite skin from the PP and Coremat Xi core, respectively (Fig. 3). The average values obtained for laminates $\mathrm{B}$ and $\mathrm{C}$ were lower (35 and 22\%, respectively) than the average value reported for laminate A. Three-point bending flexural tests were conducted to determine the suitability of 
the sandwich-structured composites for use in lightweight support structures. The stress-strain curves plotted for the composites tested were similar, with no clear yield point. The damage in the form of delamination, i.e. separation of the carbon and glass fiber reinforcement from the polymer core, was related to a drop in the adhesive strength (Table 2).

Table 1: Results of the impact resistance tests for the different composite laminates.

\begin{tabular}{|c|c|c|c|}
\hline $\begin{array}{c}\text { Laminate symbol } \\
\text { overall thickness } \\
\text { (core type and thickness) }\end{array}$ & Specimen No & Energy (work), J & $\begin{array}{l}\text { Impact resistance, } \mathrm{R}_{\mathrm{e}} \\
\mathrm{kJ} / \mathrm{m}^{2}\end{array}$ \\
\hline A & A1 & 7.383 & 137.99 \\
\hline \multirow{3}{*}{$\begin{array}{l}5 \mathrm{~mm} \text { thick } \\
\text { (Soric XF - } 2 \mathrm{~mm} \text { ) }\end{array}$} & $\mathrm{A} 2$ & 6.986 & 130.58 \\
\hline & $\mathrm{A} 3$ & 7.099 & 132.68 \\
\hline & & & 133.75 \\
\hline B & B1 & 17.801 & 91.64 \\
\hline \multirow{3}{*}{$\begin{array}{c}18.5 \mathrm{~mm} \text { thick } \\
\text { (polypropylene PP - } 15 \mathrm{~mm} \text { ) }\end{array}$} & B2 & 16.288 & 83.85 \\
\hline & B3 & 16.765 & 86.30 \\
\hline & & & 87.26 \\
\hline $\mathrm{C}$ & $\mathrm{C} 1$ & 5.701 & 106.55 \\
\hline \multirow{3}{*}{$\begin{array}{c}8 \mathrm{~mm} \text { thick } \\
\text { (Coremat Xi }-3 \mathrm{~mm})\end{array}$} & $\mathrm{C} 2$ & 5.459 & 102.02 \\
\hline & $\mathrm{C} 3$ & 5.646 & 105.52 \\
\hline & & & 104.70 \\
\hline
\end{tabular}

a)

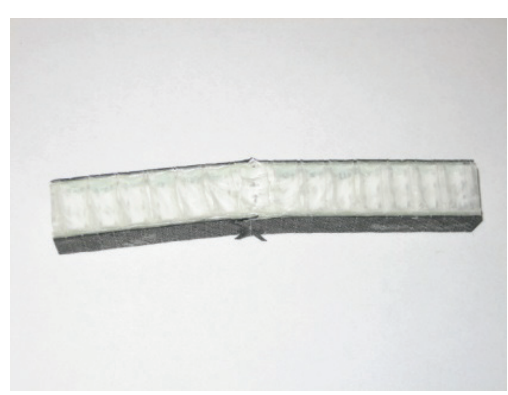

b)

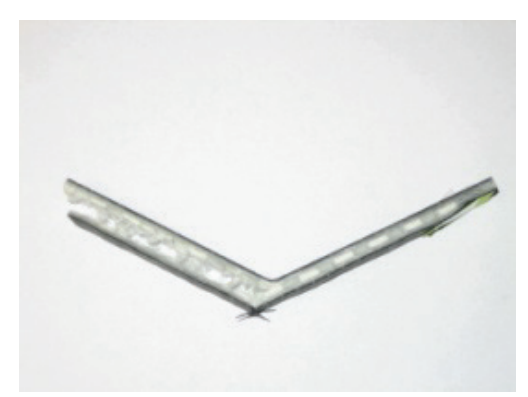

Fig. 3: Kompozyt z rdzeniem w postaci plastra miodu: $a-z P P ; b-z$ Coremat Xi.

a)

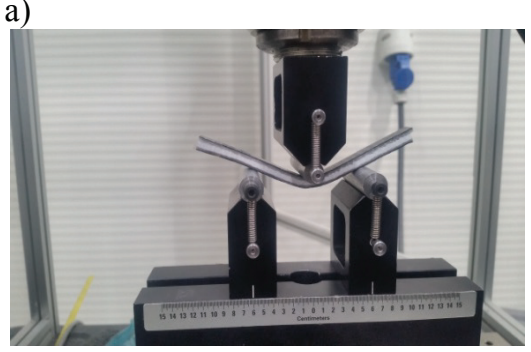

b)

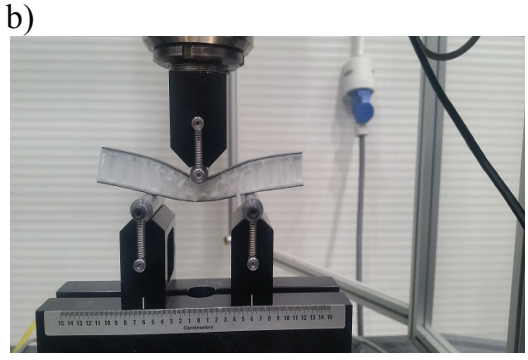

c)

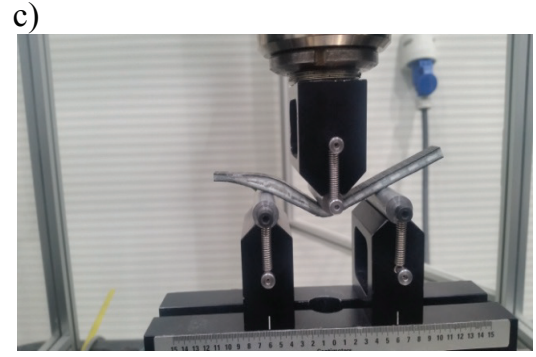

Fig. 4: Specimens subjected to three-point bending with an Instron 8874: $a$-Soric XF (Chatys et al., 2017), b-PP honeycomb, c-Coremat Xi honeycomb.

The highest average adhesive strength was reported for laminate A and it was equal to $128.18 \mathrm{MPa}$ (Fig. 5). The lowest was obtained for laminate $\mathrm{C}$ (Table 2). However, laminate $\mathrm{C}$ was characterized by higher energy absorption capacity and a smoother slope (Fig. 5) than laminate A. No such observations were made about laminate $B$. 
Table 2: Peak loads and peak stresses for the different composites.

\begin{tabular}{lccc}
\hline Properties/Laminate & A & B & C \\
\hline Peak Load, kN & 0.364 & 0.355 & 0.225 \\
\hline Peak Stress, MPa & 128.18 & 8.92 & 60.7 \\
\hline
\end{tabular}

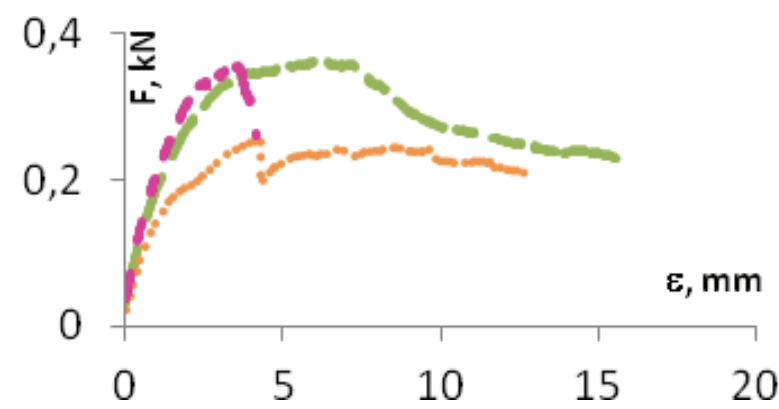

Fig. 5: Load vs. elongation: 1 - laminate A with a Soric XF core (green), 2 - laminate B with a PP honeycomb core (orange), 3 - laminate $C$ with a Coremat Xi core (pink)

\section{Conclusions}

The results presented in this paper can be useful to engineers working with a wide range of polymers and composite laminates to design bumpers, support structures and other elements that are exposed to impact loads. The experimental data show that there is a clear relationship between the material structure and its energy absorption capacity, with the latter determining the material application. The tests revealed that the impact absorption capacity of composites $\mathrm{C}$ and $\mathrm{A}$ was much higher than that of composite $\mathrm{B}$.

\section{References}

Chatys R. (2013) Investigation of the Effect of Distribution of the Static Strength on the Fatigue Failure of a Layered Composite by Using the Markov Chains Theory, Mechanics of Comp. Materials, 48, 6, pp.629-639, ISSN: 0191-5665.

Chatys R., Miśków G. and Miśków J. (2017) Structural modelling of the strength properties of polymer composites. In: Engineering Mechanics 2017, Brno University of Technology, Brno, pp. 250-254.

Morello L., Rossini L. R., Pia G. and Tonoli A. (2011) The Automotive Body. Springer Dordrecht Heidelberg Components Design, Vol. I, London - New York, ISBN 978-94-007-0513-5, pp. 207- 225.

Nowakowski, L. and Wijas, M. (2016) The evaluation of the process of surface regeneration after laser cladding and face milling. In: Engineering Mechanics 2016 (eds. Zolotarev, I. and Radolf, V.), IT AS CR, Prague, pp. 430433.

Roy R., H. Kweon J. and Choi J. H. (2014) Meso-scale finite element modeling of Nomex ${ }^{\mathrm{TM}}$ honeycomb cores, Advanced Composite Materials, Vol. 23, No.1 pp. 17-29.

Takosoglu J. E. (2016) Control System of Delta Manipulator with Pneumatic Artificial Muscles. In: Engineering Mechanics 2016 (eds. Zolotarev, I. and Radolf, V.), IT AS CR, Prague, pp. 546-549. 